\title{
A INDÚSTRIA EXTRATIVISTA E O APROFUNDAMENTO DA DIVISÃO INTERNACIONAL DO TRABALHO EM REGIÕES PERIFÉRICAS: O CASO DA SUZANO PAPEL E CELULOSE NO MARANHÃO
}

Allison Bezerra Oliveira ${ }^{1}$ Daniely Lima Silva²

Resumo: Este artigo analisa o processo de especialização produtiva do trabalho mediante a implantação da Suzano Papel e Celulose em Imperatriz, Maranhão. Questiona-se se estaria em curso um aprofundamento da Divisão Internacional do Trabalho, devido ao avanço da cadeia produtiva de papel e celulose. Além de revisão de literatura pertinente, analisa-se dados relativos aos trabalhadores com formação em nível superior a partir de pesquisas de campo, produção cartográfica e análise de dados coletados nas bases: RAIS, CAGED, PDET, INEP, IBGE e nas instituições de ensino superior. Como resultados, mapeou-se a cadeia de trabalho no segmento celulósico no Maranhão e verificou-se um real aprofundamento da especialização produtiva, o que reforça o papel do estado como exportador de matéria-prima.

Palavras-chave: Extrativismo arbóreo. Divisão Internacional do Trabalho. Imperatriz- MA.

\section{THE EXTRATIVIST INDUSTRY AND THE DEVELOPMENT OF THE INTERNATIONAL DIVISION OF WORK IN PERIPHERAL REGIONS: THE CASE OF SUZANO PAPEL AND CELLULOSE IN MARANHÃO}

Abstract: This paper analyzes the process of productive specialization of the work through the implementation of Suzano Papel e Celulose in Imperatriz, Maranhão. It is questioned whether a deepening of the international division of labor would be underway due to the advance of the pulp and paper production chain. In addition to reviewing relevant literature, data on workers with higher education are analyzed from field surveys, cartographic production and analysis of data collected at the bases: RAIS, CAGED, PDET, INEP, IBGE and in educational institutions higher. As a result, the chain of work in the cellulosic segment in Maranhão was mapped and there was a real deepening of the productive specialization, which reinforces the role of the state as exporter of raw material.

Keywords: Tree extractivism. International Labor Office. Imperatriz- MA.

\section{LA INDUSTRIA EXTRATIVISTA Y EL APROBADO DE LA DIVISIÓN INTERNACIONAL DEL TRABAJO EN REGIONES PERIFÉRICAS: EL CASO DEL SUZANO PAPEL Y CELULOSA EN EL MARANHÃO}

Resumen: Este artículo analiza el proceso de especialización productiva del trabajo mediante la implantación de Suzano Papel y Celulosa en Emperatriz, Maranhão. Se pregunta si se está en curso una profundización de la división internacional del

\footnotetext{
1 Universidade Estadual da Região Tocantina do Maranhão - UEMASUL, Centro de Ciências Humanas Sociais e Letras - CCHSL, Imperatriz, Brasil, allisonbzr@gmail.com, http://orcid.org/00000003-0320-5661

2 Universidade Estadual da Região Tocantina do Maranhão - UEMASUL, Centro de Ciências Humanas Sociais e Letras - CCHSL, Imperatriz, Brasil, daniely.slyma@gmail.com, http://orcid.org/0000-0002-1666-9038
} 
trabajo, debido al avance de la cadena productiva de papel y celulosa. Además de la revisión de literatura pertinente, se analizan datos relativos a los trabajadores con formación a nivel superior a partir de investigaciones de campo, producción cartográfica y análisis de datos recolectados en las bases: RAIS, CAGED, PDET, INEP, IBGE y en las instituciones de enseñanza superior. Como resultados, se mapeó la cadena de trabajo en el segmento celulósico en Maranhão y se verificó una real profundización de la especialización productiva, lo que refuerza el papel del estado como exportador de materia prima.

Palabras clave: Extractivismo arbóreo. División Internacional del Trabajo. Imperatriz- MA.

\section{Introdução}

O padrão agroexportador estabelecido no Brasil desde o período colonial introduziu no país características geoeconômicas que contribuíram ao longo dos anos para a sua manutenção na periferia mundial. No estado do Maranhão não haveria de ser diferente. Situado no que se pode considerar atualmente a mais importante fronteira agrícola nordestina, o estado tem o modelo agro-míneroexportador como uma de suas características produtivas mais marcantes (OLIVEIRA, 2019).

O modelo de reestruturação produtiva baseado em grandes projetos implicou para o estado do Maranhão intensa relação com o setor primário. Estruturou-se, assim, um modelo de enclave centrado em uma economia de fronteira, baseado na exploração exponencial de recursos, a exemplo do extrativismo arbóreo do eucalipto.

Introduzido no estado com o objetivo de servir inicialmente como fonte de energia para as indústrias de ferro-gusa, o eucalipto, ao longo dos anos, serviu de base para tentativas de subsidiar a produção de pasta de celulose. A base plantada e as características geográficas como terra barata, infraestrutura de transporte, recursos hídricos e força de trabalho em abundância permitiram a implantação da Suzano Papel e Celulose em Imperatriz a partir do ano de 2008.

A chegada dessa empresa contribuiu para a especialização produtiva do território maranhense com vistas à exploração do extrativismo arbóreo para a exportação de celulose. Isso não apenas aprofunda o papel de regiões retardatárias, como o Maranhão, no modelo de desenvolvimento desigual e combinado, como também acentua o papel do estado na periferia da Divisão Internacional do Trabalho através da reorganização, reestruturação e direcionamento da força de trabalho da 
região para atender à lógica e ao pleno funcionamento da cadeia produtiva de papel e celulose.

Dessa forma, este trabalho objetiva analisar o processo de especialização produtiva do trabalho mediante a implantação de unidade fabril da Suzano Papel e Celulose em Imperatriz, sudoeste do Maranhão. Assim, questiona-se: estaria em curso um processo de aprofundamento da Divisão Internacional do Trabalho, resultante do avanço da cadeia produtiva de papel e celulose no estado? Para esta análise, utiliza-se como recorte os trabalhadores com formação em nível superior.

Metodologicamente, além de revisão da literatura pertinente, realizou-se pesquisas de campo, produção cartográfica, análise de dados secundários sobre transformações no emprego local e nas qualificações profissionais locais advindas da implantação da indústria extrativista em questão. Os dados utilizados são de 2018 e foram coletados na Relação Anual de Indicadores Sociais (RAIS); Cadastro Geral de Empregados e Desempregados (CAGED); Programa de Disseminação das Estatísticas do Trabalho (PDET); censos do Instituto Nacional de Estudos e Pesquisas Educacionais Anísio Teixeira (INEP); Instituto Brasileiro de Geografia e Estatística (IBGE), além de instituições de ensino superior locais.

Além desta introdução e das considerações finais, este trabalho está dividido em quatro seções temáticas. Inicia-se discutindo algumas das transformações na indústria de papel e celulose no mundo, em seguida discute-se as disparidades e aprofundamentos das diferenciações mundiais em face do desenvolvimento desigual e Divisão Internacional do Trabalho. Trazendo para a escala brasileira, aborda-se $o$ papel do extrativismo na economia maranhense e a implantação da Suzano Papel e Celulose. Por fim, os resultados são discutidos na seção $O$ aprofundamento da Divisão Internacional do Trabalho no extrativismo arbóreo no Maranhão.

\section{Transformações na indústria de papel e celulose no mundo}

A indústria de transformação de papel e celulose engloba a fabricação e manufatura de variados tipos de papéis e tem como principal fonte de matéria-prima a madeira celulósica. Caracteriza-se como um processo industrial contínuo, de descontinuidades tecnológicas na produção de novas gerações de equipamentos, homogeneidade do produto e necessidade de ampla base florestal, baseada no intensivo uso da terra e da água (MONTEBELLO, 2010; OLIVEIRA et al, 2018).

Nesse contexto, no início da década de 1990, as indústrias de papel e celulose mundiais instauraram um acentuado processo de flexibilização e 
reestruturação tanto produtiva quanto tecnológica (equipamentos de processo e controle), investindo em microtecnologia, biotecnologia, inovação, criação de mercados e desenvolvimento e implantação de estratégias de organização, maximização empresarial e, sobretudo, de desconcentração espacial da produção (DAURA, 2004; OLIVEIRA, 2019).

Esse intenso processo de reestruturação das indústrias do setor pode ser compreendido observando-se mudanças em diversos aspectos: fatores estruturais, padrões tecnológicos, novas bases de competividade e mercado nas economias de escala, além do sistema produtivo, questões ambientais e modelos de concentração, desconcentração e centralização de capitais.

A reestruturação produtiva, ancorada em novas formas de organização de produção/trabalho pós-fordista, e as novas relações entre o setor primário dos países do Hemisfério Norte atuaram de forma intensiva no setor de papel e celulose, reorganizando a cadeia, cada vez mais amparada na informatização tecnológica da produção, flexibilização, programas de qualidade, classificação de produtos, uso de maior volume de recursos naturais, especialização produtiva do território e reorganização do trabalho e do trabalhador.

A indústria de papel e celulose brasileira foi inserida na cadeia produtiva mundial em meados dos anos 1960, mas somente a partir dos anos 1990, em consequência das novas formas de organização industrial e combinações produtivas, é que foi incluída forte, direta e ativamente no mercado internacional. Uma vez então integrada a esse mercado, passou por uma específica transformação qualitativa em seus processos produtivos (LEITE,1997; SUZIGAN, 2000).

Assim, as transformações ao longo da cadeia produtiva de papel e celulose desenharam-se a partir dos processos de centralização e descentralização econômica entre os hemisférios Norte e Sul, constituindo um ciclo espacial da produção, organizado em amplitude global. Ou seja, reconfigurou-se a divisão territorial do trabalho em uma relação de desenvolvimento desigual e combinado entre fabricantes de produtos de alto valor agregado, como alguns países do Hemisfério Norte, e produtores de matéria-prima beneficiada, como o Brasil (OLIVEIRA, 2019).

Diante disso, tradicionais fornecedores de celulose pertencentes à cadeia produtiva internacional - como Estados Unidos, Canadá, Suécia e Finlândia - estão aos poucos descentralizando suas competências para diferentes países, a maioria de ordem periférica - como Brasil, Chile e Índia. Como os países centrais e 
industrializados optam por produzir a etapa de maior valor agregado, a exemplo da fabricação de papel e derivados, aos países periféricos é destinada a parte mais onerosa de todo o processo produtivo: o cultivo, a produção e distribuição de pasta base celulósica, conforme explica Oliveira (2019, p. 3):

Os processos de desindustrialização ocorridos nos últimos anos em países do Hemisfério Norte [...] têm ocasionado a transferência de processos iniciais da cadeia produtiva de papel e celulose, os mais onerosos do ponto de vista socioambiental (e com menor valor agregado), para países periféricos, como o Brasil, constituindo modelos de desenvolvimento desigual e combinado do mundo capitalista.

Com isso, constrói-se no modo de produção capitalista uma relação entre maior produção agregada - consequentemente, maior competividade - e produção de commodities florestais para o mercado internacional. E, desse modo, concentram-se as bases de maior valor agregado e capacidade tecnológica em países industrializados, relegando para países pobres da América Latina e do sul da Ásia modelos já não tão lucrativos do ponto de vista ambiental e do trabalho.

As transformações pelas quais passaram as indústrias de papel e celulose nas últimas três décadas tendem também a reafirmar estruturas já consolidadas no mundo capitalista, tais como a acentuação de disparidades entre o centro e a periferia, a transformação cada vez maior de países retardatários em fronteiras agrícolas e a acentuação da Divisão Internacional do Trabalho.

\section{Desenvolvimento desigual e Divisão Internacional do Trabalho}

Para Durkheim (2004, p. 324), a divisão do trabalho "aumenta simultaneamente a força produtiva e a habilidade do trabalhador, ela é a condição necessária para o desenvolvimento intelectual e material das sociedades". Essa divisão mostra-se como condição específica do sistema capitalista, à medida que a produção de mercadorias assume um papel central na especialização e diversificação técnica, potencializando a segmentação do trabalho de modo a hierarquizá-lo. Isso porque o capitalismo, em seu modo sistêmico de produção, sempre demanda hierarquias (PELIANO, 1990; POCHMANN, 2002; SANTOS, 2005).

A divisão é, portanto, requisito para expandir a produção de mercadorias e criar um ambiente de intercâmbio mercantil que ultrapassa os limites de economias regionais e nacionais, desenvolvendo o comércio entre países e acentuando a Divisão Internacional do Trabalho (POCHMANN, 2002; SANTOS, 2005). Esta, por 
definição, relaciona-se às competências e funções produtivas desenvolvidas e desempenhadas por cada país no sistema produtivo internacional. Cabe ressaltar que se refere a uma distribuição de recursos estimulada pelas atividades produtivas, pois está diretamente ligada a divisões do trabalho circunscritas a regiões e territórios nacionais (SILVA, 1997; SANTOS, 2005).

\begin{abstract}
A divisão internacional do trabalho apenas nos dá a maneira de ser do modo de produção dominante, apontando as formas geográficas portadoras de uma inovação e, por isso mesmo, carregadas de uma intencionalidade nova. É através da incidência num país da divisão interna do trabalho que as especificidades começam a repontar: a formação socioeconômica correspondente atribui um valor determinado a cada forma e a todas as formas, através da redistribuição de funções. (SANTOS, 2005, p. 61).
\end{abstract}

Desse modo, tal divisão potencializa as vantagens de cada país, sejam naturais ou artificiais, de modo a beneficiar uma produção com menores custos, atribuindo-Ihe especificações. Ou seja, não separa os países somente entre ricos e pobres, mas a partir de suas estruturas, capacidades tecnológicas e particularidades produtivas. Representa, portanto, relações complexas no interior das economias de escala mundial, como pressões desencadeadas por fundos monetários, estágios industriais, geopolíticas macroeconômicas e relações de centro-periferia.

[...] a forma centro-periferia constitui a dinâmica pela qual o capitalismo se desenvolve historicamente, originando neste movimento histórico um processo de contradição entre as economias e sociedades centrais e as periféricas, esta não é a principal contradição do sistema. Ou seja, embora devamos considerar os conflitos e disputa de interesses entre centro e periferia - caracterizados pelos blocos econômicos, monopólios tecnológicos e culturais etc. - que dividem países desenvolvidos e nãodesenvolvidos, norte e sul, ou primeiro e terceiro mundo, a contradição principal das relações sociais capitalistas reside fundamentalmente no modo de produção capitalista mesmo, ou seja, na oposição entre capital e trabalho. (LIMA FILHO, 2004, p. 57).

Nesse contexto, o avanço das transformações neoliberais, a partir da década de 1970, e a acumulação flexível contribuíram para o desenvolvimento de um tipo de trabalho mais fragmentado, polivalente, complexificado e desterritorializado. Além disso, também alicerçam estruturas cada vez mais estratificadas e hierárquicas entre os processos produtivos, os países e seus trabalhadores. Isso implica considerarmos que na estrutura produtiva mundial determinou-se tipos específicos de trabalho para determinadas regiões: os países ricos detêm processos de trabalho mais avançados e complexos, e os periféricos executam níveis mais rudimentares, mesmo os vinculados a engenharias e tecnologias (HARVEY, 2005, 2011, 2013).

Dessa forma, as nações economicamente desenvolvidas estabelecem-se como centros internacionais diante da facilidade de integração e aplicabilidade de 
sistemas microeletrônicos, nanotecnológicos, biotecnológicos e outras atividades fortemente baseadas no setor quaternário. Aos países periféricos, como o Brasil, diante de debilidades nesses e em outros setores, vincula-se a especialização produtiva do trabalho em atividades diretamente ligadas à produção e ao beneficiamento de matéria-prima, por exemplo, a produção de pasta de celulose. Sobre as implicações dessa dinâmica para o país, Pereira (2010, p. 351) destaca:

As inserções do Brasil na divisão internacional do trabalho, ou seja, as funções desempenhadas por nosso país no sistema mundial conferem, historicamente, uma condição de subordinação da nação aos interesses externos, enquanto o trabalho e os recursos voltados para o mercado interno aparecem como residuais aos olhos das políticas públicas.

O aprofundamento dessas disparidades estrutura um modelo de desenvolvimento desigual e combinado no qual diferentes níveis de integração tecnológica e processos de exploração e aplicação de força de trabalho atuam para promover mercadorias no mundo globalizado (SMITH, 1988; ALVES, 1999). Desse modo, compreende-se a ocorrência simultânea de aspectos avançados e atrasados no processo de desenvolvimento econômico dos países, o que se revela especialmente nas relações econômicas entre países ricos e periféricos.

Nessa dinâmica há uma tendência para diferenciação dos processos de trabalho e igualização no consumo. Ou seja, ao mesmo tempo em que se aprofundam especializações e segmentações da produção - alguns países destinados exclusivamente para fornecimento de matéria-prima, em contraste com outros focados em desenvolvimento tecnológico, ligados ao setor quaternário -, incentiva-se o consumo, visando padrões globais, mesmo em países pobres.

O Brasil e a indústria brasileira historicamente têm direcionado seus investimentos para atividades vinculadas ao setor primário, com vistas à produção de commodities para o mercado externo, além do complexo do petróleo. Contudo, tal direcionamento econômico acaba por desincentivar a formação de competências científicas e tecnológicas, fazendo com que dentro da Divisão Internacional do Trabalho sejamos vistos cada vez mais como país agro-mínero-exportador, vide os avanços das fronteiras agrícolas de soja e extrativismo arbóreo do eucalipto (OLIVEIRA, 2019).

\section{O papel do extrativismo na economia maranhense e a implantação da Suzano Papel e Celulose}


O extrativismo tem papel fundamental no processo de formação socioeconômica do Maranhão. A ocupação do estado esteve sempre atrelada a produtos oriundos do setor primário como: cana-de-açúcar, algodão, arroz, babaçu, carne bovina e, mais recentemente, soja e commodities agroflorestais. No Maranhão, assim como no restante do Brasil, ocorreram ciclos econômicos baseados majoritariamente na pilhagem de recursos naturais, seja no período colonial, nos movimentos de "integração nacional" ou nos atuais modelos de crescimento econômico baseados em grandes projetos (OLIVEIRA, 2018, 2019).

Assim, historicamente instituiu-se no estado um modelo de crescimento econômico baseado no paradigma sociedade-natureza, denominado "economia de fronteira", para o qual o progresso corresponde a estruturas de exploração de recursos naturais para o mercado internacional, recursos estes vistos como ilimitados.

O extrativismo em suas mais diversas formas sempre foi o foco dos processos e ciclos econômicos fixados no Maranhão. Ancorada nas grandes extensões de terra e condições geográficas favoráveis, a produção do setor primário tornou-se, então, o seguimento de maior contribuição para expansão e desenvolvimento econômico local.

Ao observarmos as frentes de expansão da estrutura agrícola na região maranhense, ao longo de dois séculos e meio, vê-se que a economia permaneceu circunscrita ao extrativismo e à comercialização de produtos primários, cuja demanda e valor eram proeminentes no mercado internacional. Em decorrência disso, a atividade produtiva desenvolvida resumiu-se à coleta de matéria-prima (OLIVEIRA, 2019).

A expansão extrativista arbórea tem sido uma das principais promessas do agronegócio nacional. A produção tem se expandido fortemente por todo o território brasileiro em busca de redução de custos e aumento de produtividade. No Maranhão, essa expansão está diretamente vinculada aos processos de reestruturação produtiva baseados em grandes projetos agro-mínero-exportadores na Amazônia Legal, como o Projeto Grande Carajás, e a construção de infraestrutura de transporte, como a rodovia Belém-Brasília (BR-010) e as ferrovias Carajás-Itaqui e Norte-Sul.

A partir da década de 1980, instalaram-se na cidade de Açailândia empresas do complexo de produção de ferro-gusa, aproveitando o incentivo para projetos dessa natureza, a proximidade com matéria-prima e infraestrutura para escoamento 
da produção. Do plantio do eucalipto veio o carvão, principal matriz de energia para alimentar as caldeiras. E assim, com a produção de carvão para o complexo de ferro-gusa, o eucalipto foi inserido em grande escala no sul do Maranhão.

Na década de 1990, a então Companhia Vale do Rio Doce (CVRD) iniciou vasto plantio de áreas de eucalipto destinadas à produção de celulose no Maranhão, sobretudo na área de influência da Estrada de Ferro Carajás. Essa iniciativa deu início, no estado, ao primeiro projeto do Programa de Polos Florestais da Amazônia Oriental. Estruturado pela indústria de celulose (o projeto Celmar) e focado na região tocantina do estado, devido ao potencial hídrico local, o megaconsórcio foi formado pelo grupo Risipar (associação da Votorantim com a Ripasa), com 55\% do capital; pela CVRD, com 30\%; e a empresa japonesa Nissho Iwai Corporation, com 15\%.

Outro empreendimento incluído no Programa Polos Florestais, ainda na forma de projeto, foi o Florar, cujas empresas consorciadas eram Aracruz Celulose (40\%), CVRD (20\%) e empresas escandinavas (40\%). Com foco na celulose de fibra curta branqueada de eucalipto, a perspectiva de produção era de 500 mil toneladas/ano.

A base plantada por esses primeiros empreendimentos, aliada aos condicionantes geográficos (recursos hídricos em abundância, terra barata, grande oferta de força de trabalho e infraestrutura para escoamento da produção até o Porto do Itaqui) e ao processo de reestruturação da indústria de papel e celulose no mundo, atraiu para o estado do Maranhão a implantação de unidade fabril da Suzano e a instauração de sua cadeia produtiva. 
Figura 1 - Cadeia produtiva de papel e celulose

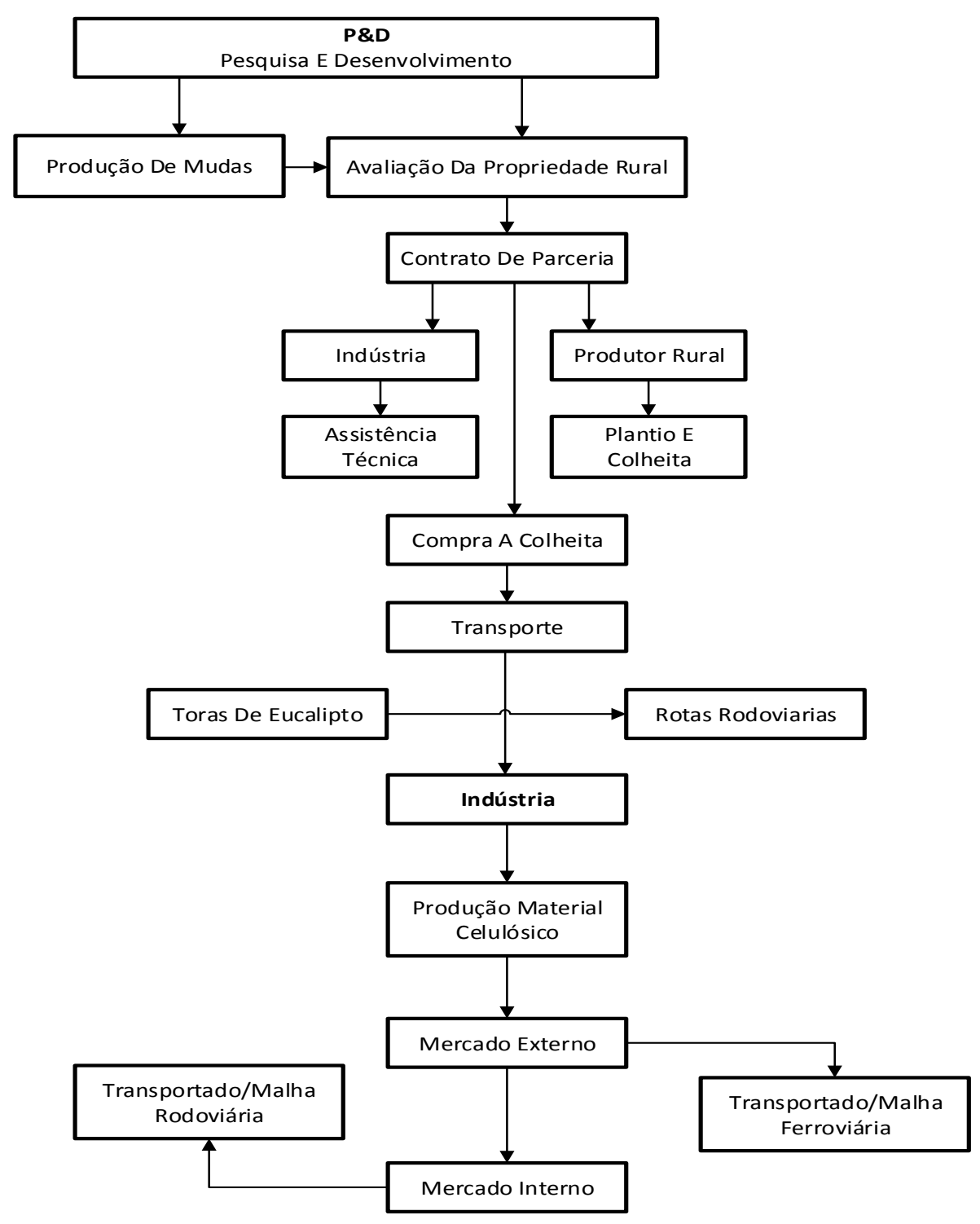

Fonte: Organizado pelos autores com base em Oliveira (2018)

A cadeia produtiva de papel e celulose industrial (Figura 1) é composta por etapas de processos contínuos e consecutivos de operações técnicas de extração, produção e circulação da matéria-prima até o mercado consumidor. Apresenta as diversas etapas ou estágios de produção e os inúmeros agentes, insumos, máquinas, equipamentos e demais elementos necessários para 0 seu desenvolvimento.

Mais do que meramente apresentar as etapas produtivas, a figura representa a dinâmica de uso das multiplicidades geoeconômicas maranhenses e apresenta elementos de transformação no espaço geográfico local. Dessa forma, permite-nos compreender, metodologicamente, a partir de cada etapa, processos de acentuação da divisão do trabalho mediante especializações produtivas. 


\section{O aprofundamento da Divisão Internacional do Trabalho no extrativismo arbóreo no Maranhão}

As transformações advindas da revolução técnico-científico-informacional e impostas pelo modelo de acumulação flexível desencadearam sucessivos processos de reestruturação produtiva na atividade industrial mundial. $O$ mais expressivo, talvez, esteja na desterritorialização de processos fabris dos países ricos para os periféricos. Essa dinâmica acentua o modelo de desenvolvimento desigual e combinado e aprofunda a Divisão Internacional do Trabalho, determinando quem produz o quê.

Nesse sentido, observa-se uma intensificação da especialização produtiva do trabalho nos países periféricos, calcada na exploração exponencial de recursos naturais para exportação. A implantação da Suzano Papel e Celulose no Maranhão representa bem esse processo.

Para que o processo de reprodução do capital mantenha-se constante, a cadeia produtiva de papel e celulose deve estar bem estabelecida e funcionar de modo satisfatório. Além disso, a força de trabalho, que do ponto de vista econômico é o principal elemento produtor de riqueza, deve ser especializada, organizada, dividida e subordinada à lógica dominante. É na divisão do trabalho que o modelo de produção dos grandes atores hegemônicos impõe sua ordem socioeconômica.

No caso da Suzano, o processo de divisão do trabalho ampara-se não só no discurso de geração de emprego e renda como também na expansão dos cursos de Engenharia nas instituições públicas e privadas do município de Imperatriz. Em um primeiro momento, houve forte demanda para construção civil da fábrica, concomitantemente à contratação e ao treinamento de trabalhadores para atuar na indústria quando do início de suas operações.

Dados da Relação Anual de Indicadores Sociais (RAIS) quanto aos níveis admissionais na indústria de transformação e na construção civil evidenciam essa demanda. O Gráfico 1 concentra dados de 2003 a 2015 e revela muito claramente um aumento no número de admissões funcionais formais nesses segmentos, sobretudo entre 2008 e 2013, etapa de construção da fábrica da Suzano. 
Gráfico 1 - Número de admissões na indústria de transformação e na construção civil

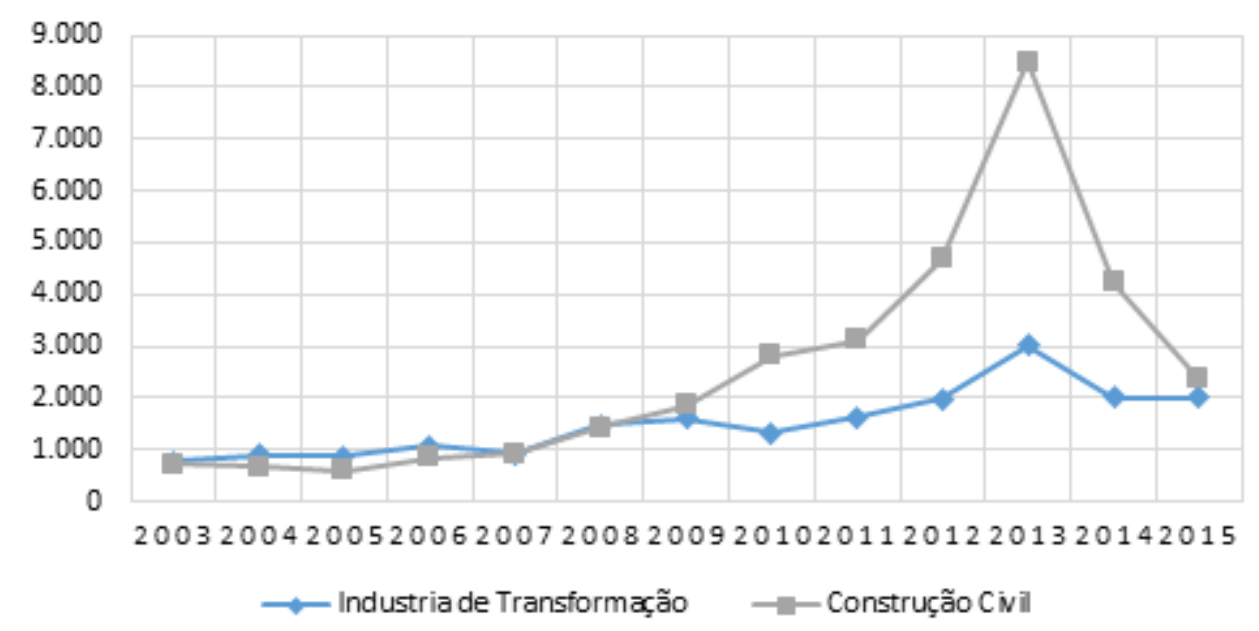

Fonte: Dados da RAIS e do PDET (2018), organizados pelos autores (2019)

As transformações correntes, aliadas ao discurso de geração de emprego e renda, acentuam no imaginário popular perspectivas de inserção profissional no mercado formal. Nesse contexto, as limitações de qualificação formal existentes em regiões periféricas como o Maranhão são supridas por grandes corporações educacionais, como as holdings Kroton e Wyden, que, atraídas pela demanda, ofertam cursos superiores direcionados para a cadeia produtiva de papel e celulose. Observa-se no Quadro 1, abaixo, a expansão da oferta de 2011 a 2018.

Quadro 1 - Anos de criação e oferta de cursos de Engenharia em Imperatriz - MA

\begin{tabular}{|c|c|c|c|c|c|c|c|}
\hline Instituição & Cursos & 2011 & 2013 & 2015 & 2016 & 2017 & 2018 \\
\hline UEMASUL & Engenharia Florestal & $x$ & $x$ & $x$ & $x$ & $x$ & $x$ \\
\hline IFMA & Engenharia Elétrica & & $x$ & $\bar{x}$ & $x$ & $x$ & $x$ \\
\hline Ceuma & Engenharia Civil & & $x$ & $x$ & $x$ & $x$ & $x$ \\
\hline Ceuma & $\begin{array}{l}\text { Engenharia de } \\
\text { Producãa }\end{array}$ & & $\mathrm{x}$ & $x$ & $\mathrm{x}$ & $x$ & $x$ \\
\hline Pitágoras & Engenharia Civil & & & $x$ & $x$ & $x$ & $x$ \\
\hline Pitágoras & $\begin{array}{l}\text { Engenharia de } \\
\text { Produção }\end{array}$ & & & $x$ & $x$ & $x$ & $x$ \\
\hline Pitágoras & Engenharia Elétrica & & & & $x$ & $x$ & $x$ \\
\hline Pitágoras & Engenharia Mecânica & & & & $x$ & $x$ & $x$ \\
\hline Wyden & Engenharia Civil & & & & & $x$ & $x$ \\
\hline Wyden & $\begin{array}{l}\text { Engenharia de } \\
\text { Produção }\end{array}$ & & & & & $x$ & $x$ \\
\hline Wyden & Engenharia Elétrica & & & & & $x$ & $x$ \\
\hline Wyden & Engenharia Mecânica & & & & & $x$ & $x$ \\
\hline Wyden & Engenharia Química & & & & & & $x$ \\
\hline
\end{tabular}

Fonte: Pesquisa de campo. Dados organizados pelos autores (2019) 
Embora exista um expressivo aumento da oferta de outros cursos superiores, cabe destacar que o primeiro curso de Engenharia em todo o sul do Maranhão passou a ser ofertado somente a partir de 2011. O curso de Engenharia Florestal, por exemplo, é o único no estado, em meio à expansão de áreas destinadas ao cultivo de eucalipto para atender ao fornecimento de matéria-prima. Cursos de outros tipos de Engenharia também acompanham essa especialização do trabalho com foco na cadeia produtiva de papel e celulose.

Como resultado, houve um aumento significativo na contratação de engenheiros em empregos formais (Gráfico 2). Os postos de trabalho, entretanto, não foram preenchidos somente por mão de obra local, pois muitos migrantes laborais deste segmento foram atraídos para Imperatriz, vindos de outras partes do país, principalmente da região que, aglomerada, concentra competências deste segmento.

Gráfico 2 - Evolução no número de admissões de engenheiros em Imperatriz - MA

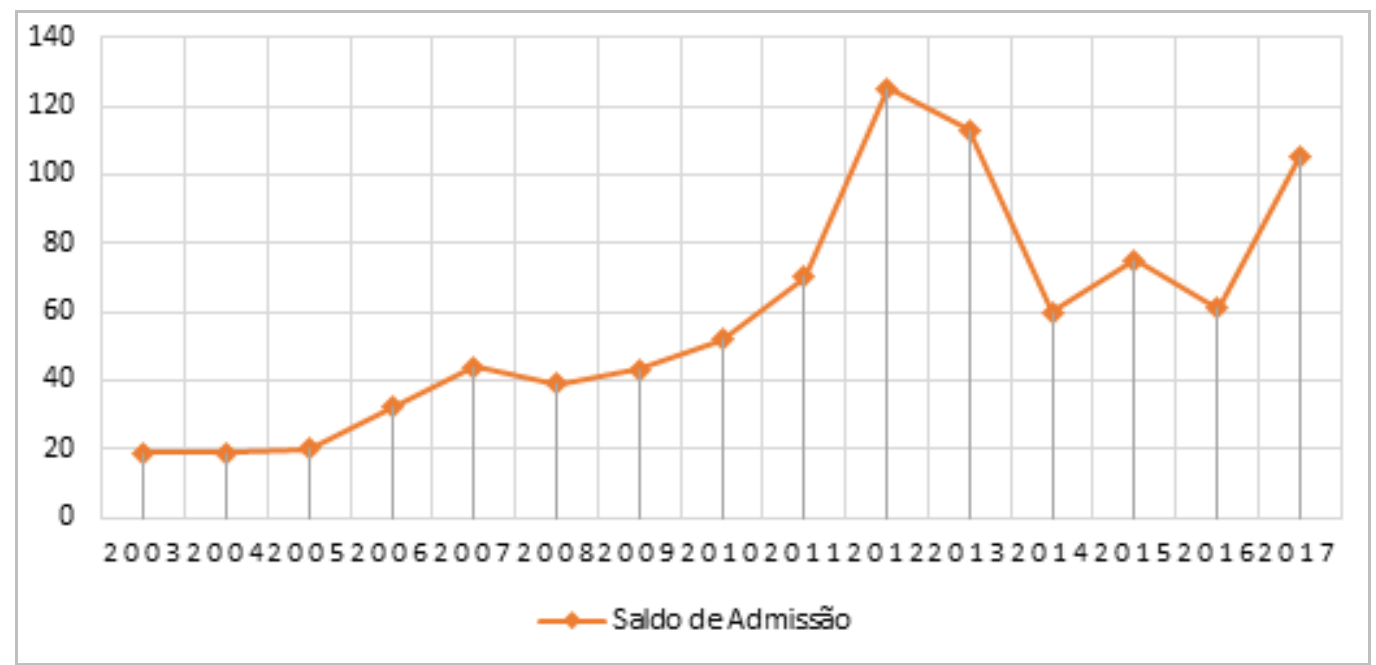

Fonte: Dados da RAIS e do PDET (2018), organizados pelos autores (2019)

Observa-se, portanto, um salto no número de contratações em especial a partir de 2009, com crescimento expressivo até 2013, quando registrou-se uma leve queda, e oscilação a partir de 2014. Vale destacar que somente a partir de 2008, com o início da implantação da Suzano, é que engenheiros mecânicos e engenheiros de produção aparecem como empregos formais cadastrados no município de Imperatriz. 
Quadro 2 - Principais profissões de nível superior contratadas em emprego formal em Imperatriz MA

\begin{tabular}{|c|c|c|c|c|c|}
\hline Ano & \multicolumn{5}{|c|}{ Profissões de nível superior mais contratadas (2013-2017) } \\
\hline 2013 & $\begin{array}{l}\text { Engenheiro } \\
\text { Mecânico }\end{array}$ & $\begin{array}{l}\text { Gerente de Produção e } \\
\text { Operações florestais }\end{array}$ & $\begin{array}{l}\text { Engenheiro } \\
\text { de Produção }\end{array}$ & Contador & $\begin{array}{l}\text { Analista de } \\
\text { Pesquisa de } \\
\text { Mercado }\end{array}$ \\
\hline 2014 & $\begin{array}{l}\text { Médico do } \\
\text { Trabalho }\end{array}$ & $\begin{array}{l}\text { Supervisor da Área } \\
\text { Florestal }\end{array}$ & $\begin{array}{l}\text { Engenheiro } \\
\text { Mecânico }\end{array}$ & Administrador & $\begin{array}{l}\text { Engenheiro } \\
\text { de Produção }\end{array}$ \\
\hline 2015 & $\begin{array}{l}\text { Engenheiro } \\
\text { Florestal }\end{array}$ & $\begin{array}{l}\text { Gerente de Projetos e } \\
\text { Serviços de } \\
\text { Manutenção }\end{array}$ & $\begin{array}{l}\text { Supervisor } \\
\text { da Área } \\
\text { Florestal }\end{array}$ & $\begin{array}{l}\text { Engenheiro de } \\
\text { Produção }\end{array}$ & $\begin{array}{l}\text { Gerente de } \\
\text { Produção e } \\
\text { Operações } \\
\text { Florestais }\end{array}$ \\
\hline 2016 & $\begin{array}{l}\text { Engenheiro } \\
\text { Mecânico }\end{array}$ & $\begin{array}{l}\text { Engenheiro Químico } \\
\text { (Papel e Celulose) }\end{array}$ & $\begin{array}{l}\text { Engenheiro } \\
\text { de Produção }\end{array}$ & $\begin{array}{l}\text { Engenheiro } \\
\text { Mecânico }\end{array}$ & $\begin{array}{l}\text { Engenheiro } \\
\text { Mecânico } \\
\text { Industrial }\end{array}$ \\
\hline 2017 & $\begin{array}{l}\text { Engenheiro } \\
\text { Florestal }\end{array}$ & $\begin{array}{l}\text { Engenheiro Químico } \\
\text { (Papel e Celulose) }\end{array}$ & $\begin{array}{l}\text { Engenheiro } \\
\text { de Produção }\end{array}$ & $\begin{array}{l}\text { Engenheiro } \\
\text { Mecânico }\end{array}$ & $\begin{array}{l}\text { Gerente de } \\
\text { Produção e } \\
\text { Operações } \\
\text { Florestais }\end{array}$ \\
\hline
\end{tabular}

Fonte: Dados da RAIS e do PDET (2018), organizados pelos autores (2019)

Conforme o Quadro 2, das cinco profissões de nível superior com mais empregabilidade formal, segundo dados da Relação Anual de Indicadores Sociais (RAIS) e do Programa de Disseminação das Estatísticas do Trabalho (PDET), de 2013 a 2017, a maioria tem relação direta ou indireta com a cadeia de papel e celulose.

Esses resultados tanto acentuam os processos de especialização do trabalho em nível superior quanto contribuem para o fortalecimento de instituições de ensino superior, sobretudo privadas, na oferta de cursos de graduação voltados para a cadeia. Há, dessa forma, não só um aumento vertiginoso da oferta de cursos, mas principalmente da procura destes, como pode ser observado no Gráfico 3, a seguir.

Gráfico 3 - Evolução de matrículas em cursos superiores em engenharias e afins em Instituições de Ensino Superior públicas e privadas 2009 - 2017, em Imperatriz - MA

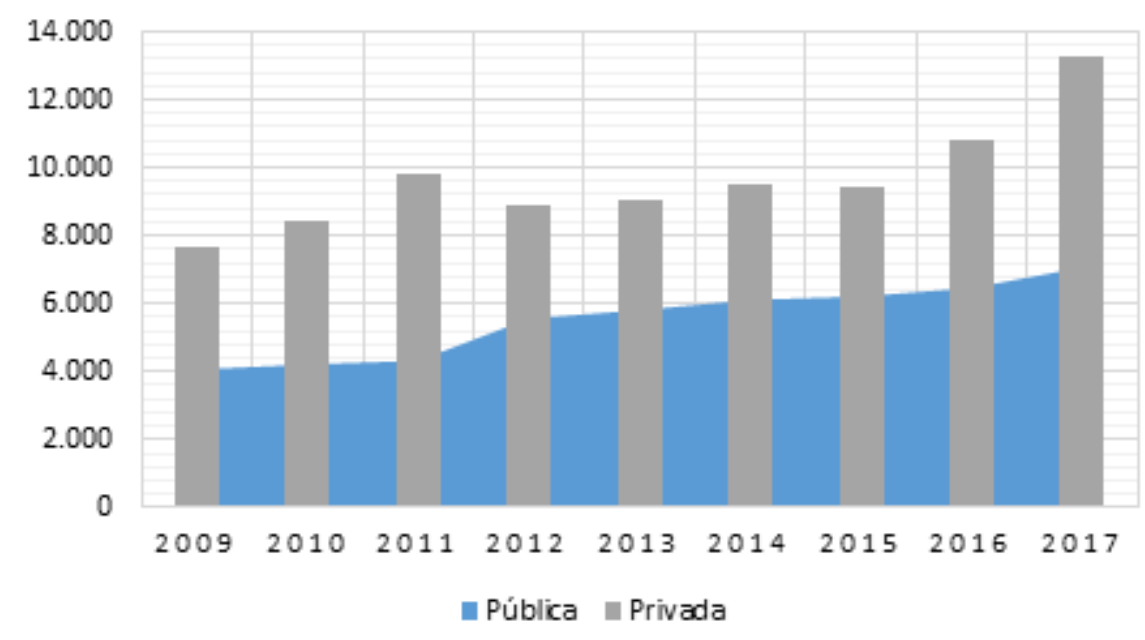


O Gráfico 3 destaca a evolução e disparidade entre instituições públicas e privadas, justamente pelo quantitativo de oferta de cursos. Contudo, a evolução de matrículas não se refere apenas aos cursos de Engenharia, mas também a outros cursos relacionados a serviços complementares demandados pela cadeia de papel e celulose, como Arquitetura, Administração, Ciência da Informação e outros.

As demandas impostas pela Suzano e sua cadeia produtiva consolidam o processo de especialização e aprofundamento do Maranhão na Divisão Internacional do Trabalho à medida que contribuem para a reprodução do capital agroexportador, atraindo força de trabalho em abundância e reserva em todos os níveis de produção.

A Figura 2, construída a partir de dados secundários e pesquisa de campo, apresenta a sequência dos processos produtivos e a especialização do trabalho em nível superior e técnico. $\mathrm{Na}$ fase inicial de Pesquisa \& Desenvolvimento, atuam engenheiros florestais, ambientais, analistas e técnicos florestais na preparação da base florestal para plantio. 
Figura 2 - Especialização produtiva do trabalho na cadeia produtiva de papel e celulose no Maranhão
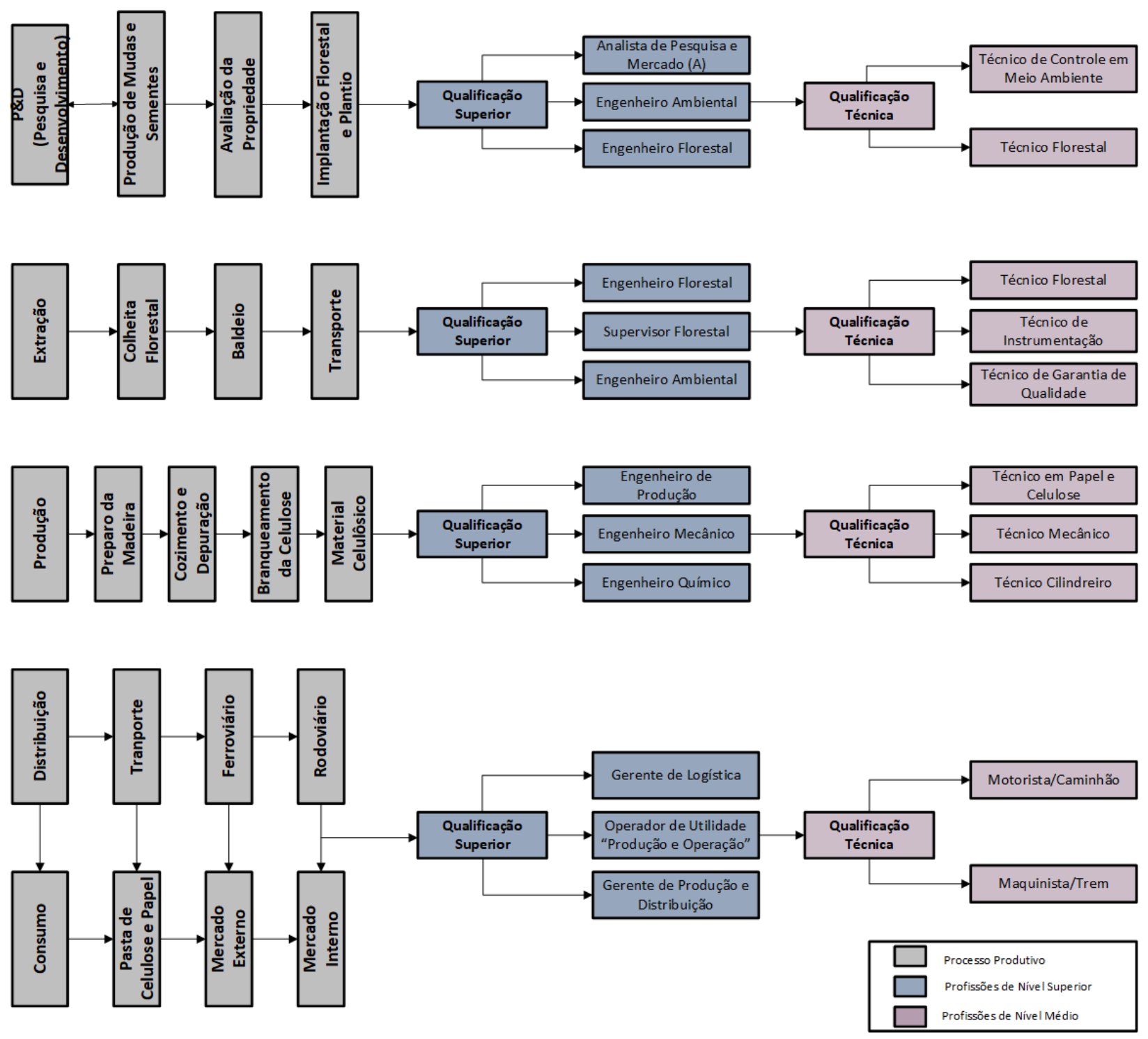

Fonte: Os autores (2019)

De modo semelhante, a extração do eucalipto para o transporte de matériaprima bruta é realizada por conexões entre redes rodoviárias, como a BelémBrasília, e rodovias estaduais e municipais que mobilizam o transporte até a fábrica onde se inicia o processo químico de transformação do eucalipto em pasta de celulose, pelo trabalho de engenheiros químicos, de produção, mecânicos e técnicos.

Em última etapa de distribuição da matéria-prima beneficiada, há participação de profissionais do segmento de logística, administração e gerenciamento de qualidade e processos produtivos. Há também conexão com outros trabalhadores cuja condição de trabalho é mais precarizada, como motoristas de caminhão, que normalmente são terceirizados ou autônomos, sem vínculo efetivo com a empresa. 
Figura 3 - Ciclo de trabalho frente à especialização produtiva do Maranhão

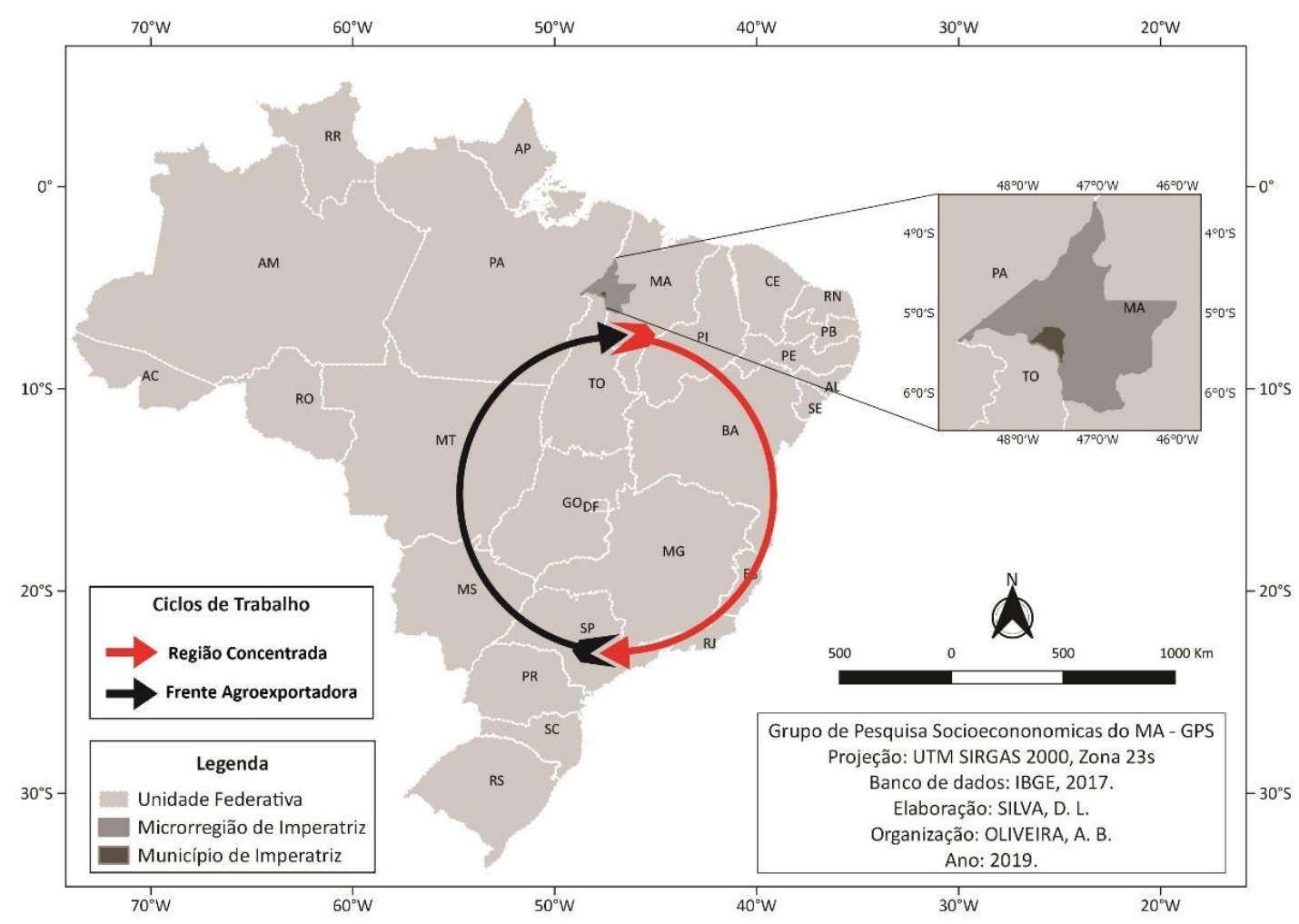

Fonte: Os autores (2019)

As transformações advindas do aprofundamento da divisão, agora territorial, do trabalho no Maranhão contribuem não apenas para reorganizar a força de trabalho local, mas também, e sobretudo, para atrair trabalhadores de regiões que tradicionalmente possuem mais know-how no segmento de papel e celulose, como é o caso da região concentrada (Figura 3). A mobilidade do capital oriunda das reestruturações que levam novas indústrias de celulose a se instalarem em regiões de frentes agrícolas também leva à mobilidade de força de trabalho em reserva.

Há, desta forma, assim como apresentado na Figura 3, uma reorganização da mobilidade do trabalho em atividades referentes ao extrativismo arbóreo no Brasil. Estados como Bahia, Maranhão, Tocantins, Piauí e Pará, no seio da economia de fronteira, tornam-se indispensáveis no reordenamento de fluxos laborais e aprofundamento da divisão territorial do trabalho brasileira.

\section{Considerações finais}

A implantação da Suzano Papel e Celulose no município de Imperatriz, porção orientação da Amazônia Legal maranhense, acentuou os modelos 
anteriormente instituídos na região, baseados em projetos de reestruturação produtiva e voltados para indústrias extrativistas. Além disso, consolidou uma economia de enclave, baseada na pilhagem irrestrita e exponencial de recursos naturais. Assim como ocorre com a soja no sul do estado, o extrativismo arbóreo estabeleceu o papel agroexportador da fronteira agrícola maranhense na economia globalizada.

No bojo dessas transformações, há inegavelmente um aprofundamento da Divisão Internacional do Trabalho frente à especialização de trabalhadores para atuar na cadeia produtiva de papel e celulose. Tal processo pode ser compreendido a partir do aumento do número de cursos superiores ofertados para qualificação profissional no segmento, além da evolução expressiva do número de matrículas e de transformações no emprego formal local.

O aumento nas taxas de empregabilidade acentua no imaginário popular 0 discurso de emprego e renda e reestrutura a força de trabalho em direção à lógica econômica predominante. Assim, trabalhadores, instituições, prestadores de serviços, setores produtivos e outros elementos espaciais são convocados a atuar sistematicamente em direção a um ator hegemônico, o que tipifica ainda mais o Maranhão em um modelo de trabalho e exploração de recursos naturais extremamente precário e predatório, inserindo o estado na periferia do modelo produtivo global de exportação de commodities agroflorestais.

\section{REFERÊNCIAS}

ALVES, G. Trabalho e mundialização do capital: a nova degradação do trabalho na era da globalização. 2. ed. Londrina: Editora Praxis, 1999. CADASTRO GERAL DE EMPREGADOS E DESEMPREGADOS (CAGED).

Empregabilidade, profissões e perfis profissionais no emprego no Brasil em 2017. Brasília: MTE, 2018. Disponível em: https://caged.maisemprego.mte.gov.br/portalcaged/. Acesso em: 18 abr. 2018.

DAURA, S. P. Análise do setor de celulose e papel na era da globalização: um olhar sobre sua produção e mão-de-obra. 2004. Tese (Doutorado em Ciências Sociais) Universidade Estadual de Campinas, Campinas, 2004.

DURKHEIM, E. Da divisão do trabalho social. 2. ed. São Paulo: Martins Fontes, 2004. HARVEY, D. A produção capitalista do espaço. São Paulo: Annablume, 2005.

HARVEY, D. O enigma do capital: e as crises do capitalismo. São Paulo: Boitempo, 2011. HARVEY, D. Os limites do capital. São Paulo: Boitempo, 2013.

INSTITUTO BRASILEIRO DE GEOGRAFIA E ESTATÍSTICA (IBGE). Produção extrativista e da silvicultura no Brasil 2017. [Rio de Janeiro]: IBGE, 2018. Disponível em: https://www.ibge.gov.br/. Acesso em: 14 fev. 2019.

INSTITUTO NACIONAL DE ESTUDOS E PESQUISAS EDUCACIONAIS ANÍSIO TEIXEIRA (INEP). Censo da Educação superior: Imperatriz. Brasília: INEP, 2018. Disponível em: http://www.inep.gov.br. Acesso em: 24 jan. 2019. 
LEITE, E. M. Reestruturação industrial, cadeias produtivas e qualificação. In: CARLEIAL, L.; VALLE, R. (org.). Reestruturação produtiva e mercado de trabalho no Brasil. São Paulo: Hucitec, 1997. p. 140-168.

LIMA FILHO, D. L. Dimensões e limites da globalização. Petrópolis: Vozes, 2004. MONTEBELLO, A. E. Configuração, reestruturação e mercado de trabalho do setor de celulose e papel no Brasil. 2010. Tese (Doutorado em Economia Aplicada) - Escola Superior de Agricultura Luiz de Queiroz, Universidade de São Paulo, Piracicaba, 2010. OLIVEIRA, A. B. Implantação industrial, reestruturação produtiva e alterações no mercado de trabalho no sudoeste maranhense (2008-2018). In: SANTOS, L. C.; SEABRA, G. F.; CASTRO, C. E. (org.). Geografia: trabalho, sociedade e meio ambiente. São Luís: Eduema, 2018. p. 340-360.

OLIVEIRA, A. B. et al. Cadeia produtiva de papel e celulose e transformações recentes no sudoeste maranhense. Revista Interespaço, Grajaú, v. 4, n. 12, p. 135-154, jan. 2018. OLIVEIRA, A. B. Indústria de celulose e o avanço da silvicultura do eucalipto na fronteira agrícola da Amazônia maranhense. Geosul, Florianópolis, v. 34, n. 71, p. 301-327, abr. 2019. Dossiê Agronegócios no Brasil.

PELIANO, J. C. Acumulação de trabalho e mobilidade do capital. Brasília: Editora da UnB, 1990.

PEREIRA, M. F. V. A inserção subordinada do Brasil na divisão internacional do trabalho: consequências territoriais e perspectivas em tempos de globalização. Sociedade \& Natureza, Uberlândia, v. 22, n. 2, p. 347-355, ago. 2010.

POCHMANN, M. O emprego na globalização: a nova divisão internacional do trabalho e os caminhos que o Brasil escolheu. 1. reimp. São Paulo: Boitempo, 2002.

PROGRAMA DE DISSEMINAÇÃO DAS ESTATÍSTICAS DO TRABALHO (PDET).

Estatísticas Ocupacionais no Brasil. Brasília: MTE, 2018. Disponível em:

http://portal.mte.gov.br/portal-mte/rais/. Acesso em: 29 jan. 2019.

RELAÇÃO ANUAL DE INFORMAÇÕES SOCIAIS (RAIS). Anuário Rais 2008-2017.

Brasília: MTE, 2018. Disponível em: http://portal.mte.gov.br/portal-mte/rais/. Acesso em: 22 abr. 2018.

SANTOS, M. A divisão social do trabalho como uma nova pista para o estudo da organização espacial e da urbanização nos países subdesenvolvidos. In: SANTOS, M. Da totalidade ao lugar. São Paulo: EDUSP, 2005. p. 55-75.

SILVA, L. H. Divisão social do trabalho: divisão sexual do trabalho. In: CATTANI, A. D. (org.). Trabalho e tecnologia: dicionário crítico. Petrópolis: Vozes, 1997. p. 292.

SMITH, N. Desenvolvimento desigual. Rio de Janeiro: Bertrand, 1988.

SUZIGAN, W. Indústria brasileira: origem e desenvolvimento. São Paulo: Hucitec;

Campinas: Ed. da Unicamp, 2000.

\title{
NOTAS DE AUTOR
}

\section{CONTRIBUIÇÃO DE AUTORIA}

\begin{abstract}
Allison Bezerra Oliveira - Concepção. Coleta de dados, Análise de dados, Elaboração do manuscrito, revisão e aprovação da versão final do trabalho

Daniely Lima Silva- Concepção e elaboração do manuscrito. Coleta de dados, Participação ativa da discussão dos resultados, revisão e aprovação da versão final do trabalho.
\end{abstract}

\section{FINANCIAMENTO}

Edital nํ 002/2018 - UNIVERSAL para o projeto de pesquisa "Especialização produtiva e uso competitivo do território no sudoeste maranhense pela cadeia de papel e celulose: técnica, terra e trabalho" na Fundação de Amparo à Pesquisa e ao Desenvolvimento Científico e Tecnológico do Maranhão - FAPEMA. Coordenado pelo Grupo de Pesquisas Socioeconômicas do MA - GPS.

\section{CONSENTIMENTO DE USO DE IMAGEM}

Não se aplica. 
APROVAÇÃO DE COMITÊ DE ÉTICA EM PESQUISA

Não se aplica.

CONFLITO DE INTERESSES

Não se aplica.

\section{LICENÇA DE USO}

Este artigo está licenciado sob a Licença Creative Commons CC-BY. Com essa licença você pode compartilhar, adaptar, criar para qualquer fim, desde que atribua a autoria da obra.

\section{HISTÓRICO}

Recebido em: 13-06-2019

Aprovado em: 25-08-2019 